\title{
Exsudação de Ácidos Orgânicos em Rizosfera de Plantas DANINHAS ${ }^{1}$
}

\author{
Organic Acid Exudation in the Rizosphere of Weeds
}

SILVA, F.A.M. ${ }^{2}$, NOGUEIRA, F.D. ${ }^{3}$; RIBEIRO, L.L. ${ }^{2}$; GODINHO, A. ${ }^{2}$ e GUIMARÃES, P.T.G. ${ }^{4}$

\begin{abstract}
RESUMO - Com o objetivo de identificar e quantificar os ácidos orgânicos na rizosfera de plantas daninhas encontradas em lavouras cafeeiras, foram coletadas amostras de rizosfera de Bidens pilosa (picão-preto), Alternanthera ficoidea (apaga-fogo), Taraxacum officinale (dentede-leão) Amaranthus deflexus (caruru), na Fazenda Experimental da EPAMIG (Empresa de Pesquisa Agropecuária de Minas Gerais), em Lavras-MG, as quais foram submetidas à extração e analisadas por Cromatografia Líquida de Alta Eficiência (CLAE). Foram identificados, na rizosfera das plantas estudadas, os ácidos oxálico, cítrico, acético, butírico e propiônico, sendo os dois primeiros encontrados em maiores concentrações, em relação aos demais. As maiores concentrações dos ácidos identificados ocorreram em B. pilosa.
\end{abstract}

Palavras-chave: CLAE, extração de ácidos orgânicos, Bidens pilosa, Alternanthera ficoidea, Taxaxacum officinale, Amaranthus deflexus.

\begin{abstract}
In order to identify and quantify organic acids in the rizosphere of weeds infesting coffee plantations, the rizosphere samples of the weeds Bidens pilosa, Alternanthera ficoidea, Taraxacum officinale, Amaranthus deflexus were collected at the Experimental Farm of EPAMIG - Lavras-MG, Brazil. The samples were submitted to extraction and analyzed by High Performance Liquid Chromatography (HPLC). Oxalic, citric, acetic, butyric and propionic acids were identified in the rizosphere of the studied plants. The first two were found in larger concentrations and the largest concentrations occurred in B. pilosa.
\end{abstract}

Key words: HPLC, organic acid extraction, Bidens pilosa, Alternanthera ficoidea, Taxaxacum officinale, Amaranthus deflexus.

\section{INTRODUÇÃO}

As raízes liberam muitos ácidos orgânicos (cítrico, málico, oxálico, butírico, acético, lático, etc.), cuja concentração depende de fatores genéticos da planta e das condições de estresse às quais estas são submetidas (Jones, 1998). Os ácidos orgânicos de baixo peso molecular ocorrem na maioria dos solos cultivados e são intermediários no metabolismo de compostos de alto peso molecular, como carboidratos, lipídeos e peptídeos. A determinação de ácidos orgânicos, no solo, é de extrema importância, já que estes podem atuar de forma direta, favorecendo a solubilidade de elementos como fósforo, potássio e zinco por processos de quelação e troca de ligantes, ou indireta, pelo estímulo da atividade microbiana (Fox \& Comerford, 1990).

A identificação da composição química do exsudato pode levar à determinação laboratorial do grau de tolerância da planta a condições de elevada acidez dos solos e baixa disponibilidade de nutrientes, principalmente fósforo. Esse método de avaliação aceleraria o processo de fitomelhoramento e a provável liberação de

Recebido para publicação em 9/1/2001 e na forma revisada em 2/7/2001.

2 Bolsista do CBP\&D-Café/EPAMIG-CTSM, Fazenda Experimental de Lavras, Caixa postal 176, 37200-000 Lavras-MG.; ${ }^{3}$ Pesquisador da EMBRAPA/EPAMIG-CTSM; ${ }^{4}$ Pesquisador da EPAMIG-CTSM. 
novas variedades para os agricultores. A importância de um trabalho de identificação da composição dos exsudatos pode significar um primeiro passo para a identificação de componentes que façam com que determinada variedade de planta tolere os solos ácidos. A opção pelo uso de plantas consideradas daninhas deve-se ao fato de que, além do potencial genético, comprovadamente, elas podem ser utilizadas na recuperação, manutenção e melhoria das condições do solo (Favero, 1998). Os objetivos deste estudo foram identificar e quantificar os ácidos orgânicos na rizosfera de algumas plantas daninhas, visando avaliar um dos fatores envolvidos no processo e na adaptação dessas plantas a solos ácidos e com baixa disponibilidade de nutrientes.

\section{MATERIAL E MÉTODOS}

Foram utilizadas amostras de rizosfera de plantas consideradas daninhas comuns em lavouras de café - Bidens pilosa (picão-preto), Alternanthera ficoidea (apaga-fogo), Taraxacum officinale (dente-de-leão) e Amaranthus deflexus (caruru) -, coletadas na Fazenda Experimental da EPAMIG (Empresa de Pesquisa Agropecuária de Minas Gerais), em Lavras-MG, em solo Podzólico Vermelho-Amarelo distrófico, textura argilosa, 2,5\% de matéria orgânica, em delineamento inteiramente casualizado, sendo coletadas três plantas de cada espécie, constituindo assim três repetições. A extração foi feita de acordo com a técnica proposta por Bazimarakenga et al. (1995), com modificações.

\section{Amostras de solo}

Amostras da rizosfera (solo aderido à raiz) foram coletadas a uma profundidade máxima de $15 \mathrm{~cm}$, para avaliar a concentração de ácidos orgânicos exsudados pelas raízes. A primeira etapa do processo consistiu em separar a raiz do solo; isso foi feito agitando-se levemente a raiz, de modo que restasse apenas pequena quantidade de solo aderida.

\section{Extração}

A combinação da mistura raiz + solo (50 g), obtida pelo procedimento descrito anteriormente, foi colocada em erlenmeyers, sendo adicionados $50 \mathrm{~mL}$ de água destilada; esse material foi agitado no escuro por 12 horas. Em seguida, o sobrenadante da mistura foi centrifugado a $10.000 \mathrm{rpm}$ por 20 minutos e filtrado em papel-filtro tipo Whatman 42. Os ácidos orgânicos foram extraídos da solução aquosa com $10 \mathrm{~mL}$ de acetato de etila. Essa solução foi aquecida em chapa a $45{ }^{\circ} \mathrm{C}$ até o ponto de parcial secura, sendo então redissolvida em $1 \mathrm{~mL}$ de água destilada.

Os ácidos orgânicos foram identificados e quantificados por CLAE (Cromatografia Líquida de Alta Eficiência), através de um cromatógrafo da marca Shimadzu, com detector UV no comprimento de onda de $230 \mathrm{~nm}$, utilizando coluna C-18 de fase reversa. O volume injetado da amostra foi de $20 \mu \mathrm{L}$. Utilizou-se como fase móvel água com $0,1 \%$ de ácido fosfórico, com fluxo de $1 \mathrm{~mL} / \mathrm{min}$. Os picos correspondentes a cada ácido foram identificados pelo tempo de retenção, utilizando-se como comparação os tempos de retenção dos padrões (Figura 1). Os dados obtidos foram submetidos à análise de variância (ANOVA), e as diferenças estatísticas foram determinadas por meio do teste de Tukey com nível de significância de 5\%. A concentração obtida foi expressa em $\mathrm{mg} \mathrm{kg}^{-1}$ de ácido na rizosfera.

\section{RESULTADOS E DISCUSSÃO}

Os cromatogramas dos ácidos são apresentados na Figura 1; a Tabela 1 mostra os ácidos avaliados, sendo identificados num tempo total de análise de $10 \mathrm{~min}$. A cromatografia líquida de alta eficiência tem sido usada freqüentemente na determinação de ácidos orgânicos de baixo peso molecular coletados em solução nutritiva, ou extraídos do solo.

As maiores concentrações de ácido oxálico foram encontradas em B. pilosa e A. ficoidea, sendo elas altas (Tabela 2) e significativamente diferentes, se comparadas às demais plantas avaliadas. Fox \& Comerford (1990), analisando a exsudação de ácidos orgânicos em solos florestais, verificaram concentrações de ácido oxálico variando entre 0,63 e $5,79 \mathrm{mg} \mathrm{kg}^{-1}$, enquanto Li et al. (1997) obtiveram concentrações de aproximadamente $3,53 \mathrm{mg} \mathrm{kg}^{-1}$ desse ácido em rizosfera de Lupin albus. Smith (1976) observou que os ácidos oxálico e acético constituem a maior percentagem de exsudados no crescimento de raízes de plantas de Pinus. 


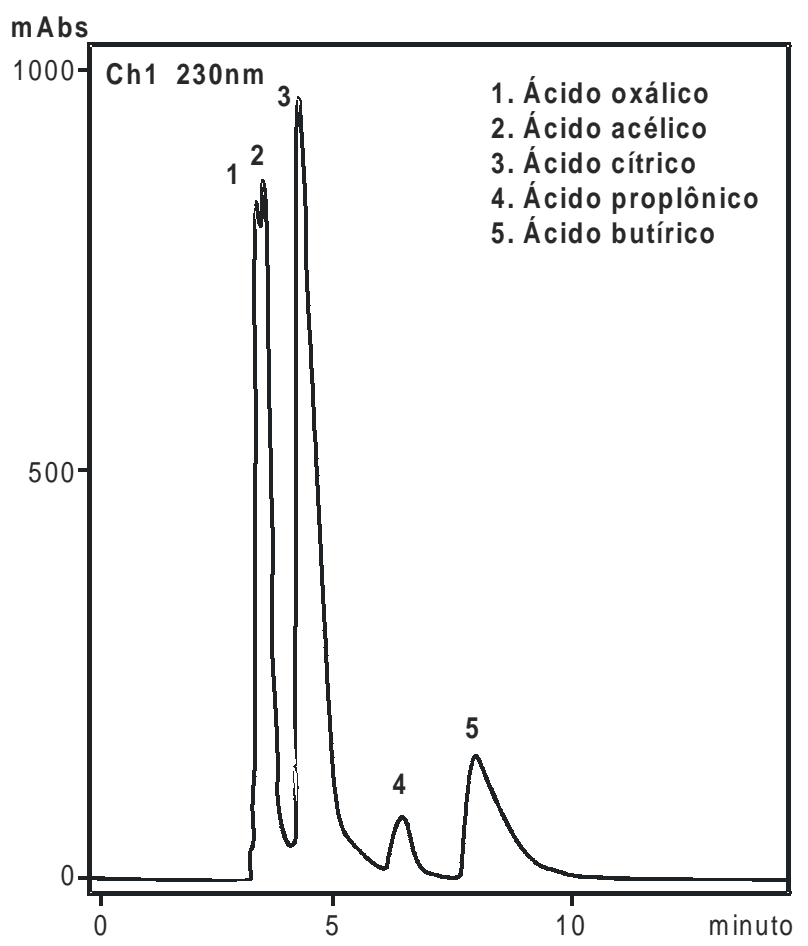

Figura 1 - Cromatograma da mistura-padrão de ácidos.

Tabela 1 - Tempos de retenção dos padrões analisados por CLAE

\begin{tabular}{|c|c|c|c|c|c|}
\hline \multirow{2}{*}{} & \multicolumn{5}{|c|}{ Ácidos } \\
\cline { 2 - 6 } & Oxálico & Acético & Cítrico & Propiônico & Butírico \\
\hline $\mathrm{T}$ & 3,7 & 4,3 & 6,4 & 7,1 & 8,9 \\
\hline
\end{tabular}

$\mathrm{T}=$ tempo de retenção $(\mathrm{min})$.
As concentrações de ácido cítrico (Tabela 2), considerado um dos componentes mais importantes envolvidos nos processos de liberação de $\mathrm{P}, \mathrm{K}, \mathrm{Zn}$ e complexação do $\mathrm{Al}$, foram maiores em B. pilosa, sendo esse valor mais alto, significativamente, do que nas outras plantas. Para o ácido acético, a maior concentração foi observada em B. pilosa. Em alguns casos, os ácidos acético e fórmico dominam o grupo dos ácidos alifáticos e representam até $75 \%$ do total de ácidos identificados. A concentração relativamente alta de ácidos como o fórmico e o acético pode ser devido à degradação de outros ácidos alifáticos (Fox \& Comerford, 1990), ou ácidos aromáticos, ou dos ácidos de origem microbiana (Heider \& Martin, 1975).

Os demais ácidos identificados (butírico e propiônico) foram encontrados em concentrações muito baixas. Tal fato pode estar relacionado com fatores genéticos e fisiológicos da planta, ou com a necessidade de maior aperfeiçoamento do método de extração, ou, ainda, com problemas de detecção apresentados pela cromatografia líquida de alta eficiência (CLAE).

A importância dos ácidos orgânicos em exsudatos radiculares e rizosfera, em geral, está relacionada ao efeito que estes podem ter na disponibilidade de nutrientes para as plantas. Tem sido mostrado que ânions orgânicos aumentam a concentração de fósforo na solução do solo (Li et al., 1997). A importância dos ácidos orgânicos de baixo peso molecular também tem sido demonstrada na redução de $\mathrm{MnO}_{4}$ (Godo \& Reisenauer, 1980). Também têm sido relatados efeitos de ácidos como o cítrico e o oxálico na liberação de K (Silva, 1999).

Tabela 2 - Teor de ácidos orgânicos na rizosfera de plantas daninhas, analisados por CLAE

\begin{tabular}{|c|c|c|c|c|c|}
\hline \multirow{3}{*}{ Espécies } & \multicolumn{5}{|c|}{ Ácidos Orgânicos } \\
\hline & Oxálico & Cítrico & Acético & Butírico & Propiônico \\
\hline & \multicolumn{5}{|c|}{ 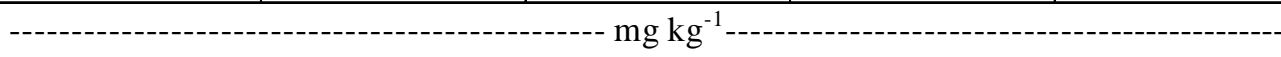 } \\
\hline A. deflexus & $3,17 \mathrm{~b}$ & $1,38 \mathrm{~b}$ & $0,66 \mathrm{a}$ & $0,00 \mathrm{~b}$ & $0,00 \mathrm{~d}$ \\
\hline T. officinale & $2,76 \mathrm{~b}$ & $0,00 \mathrm{c}$ & $0,66 \mathrm{a}$ & $0,00 \mathrm{~b}$ & $0,66 \mathrm{~b}$ \\
\hline B. pilosa & $7,77 \mathrm{a}$ & $7,27 \mathrm{a}$ & $0,74 \mathrm{a}$ & $0,54 \mathrm{a}$ & $1,25 \mathrm{a}$ \\
\hline A. ficoidea & $7,59 \mathrm{a}$ & $1,19 \mathrm{~b}$ & $0,44 \mathrm{~b}$ & $0,00 \mathrm{~b}$ & $0,35 \mathrm{c}$ \\
\hline
\end{tabular}

Letras iguais na mesma coluna não diferem entre si pelo teste de Tukey, a 5\% de probabilidade. 
Foram identificados, na rizosfera das plantas estudadas, os ácidos oxálico, cítrico, acético, butírico e propiônico, sendo os dois primeiros encontrados em maiores concentrações, em relação aos demais. As maiores concentrações dos ácidos identificados ocorreram em B. pilosa.

\section{LITERATURA CITADA}

BAZIMARAKENGA,B.; SIMARD,R.R.; LEUROX, G.D. Determination of organic acids in soil extracts by ion chromatography. Soil Biol. Biochem., v.27, p.349-356, 1995.

FAVERO, C. Potencial de plantas espontâneas e de leguminosas para adubação verde. Viçosa: UFV, 1998. 84p. Dissertação (Mestrado em Solos e Nutrição de Plantas) - Universidade Federal de Viçosa, 1998.

FOX, T.R.; COMERFORD, N.B. Low molecular weight organic acids in selected forest soil of the southwestern USA. Soil Sci. Soc. Am. J ., v.54, p.1139-1144, 1990.
GODO, G.H.; REISENAUER, H.M. Plant effects on soil manganese availability. Soil Sci. Soc. Am. J ., v.44, p.993-995, 1980.

HEIDER, K.; MARTIN, J.P. Decomposition of specifically carbon-14 labeled benzoic and cinnamic derivates in soil. Soil Sci. Soc. Am. J ., v.54, p.657-662, 1975.

JONES, D.L. Organic acids in the rhizosphere - a critical review. Plant Soil, v.205, p.25-44, 1998.

LI, M.G.; SHINANO, T.; TADANO, T. Distribution of exsudates of lupin roots in the rhizosphere under phosphorus deficient conditions. Soil Sci. Plant Nutr., v.43, p.237-245, 1997.

SILVA, V.A. Potássio em solos de regiões cafeeiras de Minas Gerais: Formas e cinética de li beração por ácidos orgânicos. Lavras: UFLA, 1999. 104p. Dissertação (Mestrado em Solos e Nutrição de Plantas) - Universidade Federal de Lavras, 1999.

SMITH, W.H. Character and significance of forest tree exudates. Ecology, v.57, p.324-331, 1976. 